\title{
An investigation on Iranian consumer behavior towards famous luxury brands
}

\author{
Seyed Hamidreza Moteshakereh ${ }^{a^{*}}$, Masoumeh sadat Abtahi ${ }^{\text {b }}$ and Ahmad Rahchamani ${ }^{\mathrm{c}}$
}

${ }^{a}$ Department of strategic Management, Qazvin Branch, Islamic Azad University, Qazvin, Iran

${ }^{b}$ Department of Humanities, Zanjan Branch, Islamic Azad University, Zanjan, Iran

${ }^{c}$ Department of strategic Management, Qazvin Branch, Islamic Azad University, Qazvin, Iran

\section{H R O N I C L E AB S T RACT}

Article history:

Received May 12, 2013

Received in revised format

30 June 2013

Accepted 28 July 2013

Available online

July 312013

Keywords:

Luxury brands

Consumer behavior

Social norms

Purchase intention

\begin{abstract}
During the past few years, there has been a growing trend on luxury good consumption among Iranian consumers. Many rich people change their mobile devices, purchase new expensive cars, etc. This paper investigates the effects of three factors including consumer perceived value, sensitivity to social norms and need for uniqueness on consumer's intention to purchase luxury products based on the theory of planned behavior. The proposed study uses clustering technique and randomly chooses a sample of 250 rich people and distributes a questionnaire among them. The study uses structural equation modeling and the implementation of the proposed model has been executed using LISREL software package. The results indicate the all three factors, consumer perceived value, sensitivity to social norms and need for uniqueness, influence consumer intention to buy luxury goods. In addition, consumer knowledge is a mediator factor between need for uniqueness and purchase intention.
\end{abstract}

(C) 2013 Growing Science Ltd. All rights reserved.

\section{Introduction}

Building and promoting luxury brands play essential role on marketing planning of luxury products. During the past few years, there have been tremendous efforts on detecting factors influences building luxury brands. Hwang and Han (2014), for instance, investigated the antecedents and consequences of brand prestige in the luxury cruise industry to provide luxury cruise managers with practical strategies for optimizing brand prestige. Achabou and Dekhili (2013) explored the extent to which sustainable development could be associated with luxury products. In particular, the survey examined the propensity of consumers to consider recycled materials in luxury purchases. They reported that incorporating recycled materials in such goods influences consumer preferences negatively and discloses a certain incompatibility between recycling and the category of luxury products. Yu et al. (2013) investigated how brand image, country of origin, and self-congruity influence internet users' purchase intention. 
Pina et al. (2013) examined the generalizability of forward and feedback impacts of durable goods and service brand extensions through a comprehensive study and four replications. The replications addressed the generalizability of empirical findings across characteristics of parent brand of luxury versus non-luxury, extension type such as goods extending into goods versus extending into services, and country. To build the generalizability of results across the studies, the first instance implemented a vote counting procedure-counting the number of substantial and non-significant results for each hypothesis. This procedure disclosed some useful patterns, such as the extension kind as a possible intervening factor. Pina et al. (2013) then used a meta-analysis method by integrating all impact sizes obtained in each experiment and their results indicated that fit between the extension and the parent brand was consistently the main factor when consumers evaluate brand extensions and the extended brands. However, brand image was more vulnerable to the perceptions of fit for parent brands associated with durable goods than for parent brands associated with services.

According to Albrecht et al. (2013), the use of brand extensions has become essential to the business model of most luxury brands. Several traditional luxury brands such as Louis Vuitton or Chanel have expanded into traditional luxury sectors beyond their core business. Albrecht et al. (2013) tried to investigate the extension-related differences between luxury and nonluxury brands by simultaneously analyzing important dimensions of parent brand value, fit, and extension category involvement on the consumer's attitude toward the brand extension, which in turn influences the postextension image of the parent brand. They reported that the predominant driver of brand extension success for both luxury and nonluxury brands was overall extension fit, followed by the consumer's involvement in the extension category. The impact of functional value of the parent brand on the extension evaluation was more essential for nonluxury brands. The hedonic value of the parent brand was detected to be of relevance in case of luxury brands. In addition, a reciprocal spillover impact between the extension evaluation and the parent brand evaluation was detected.

The knowledge of consumers' behavior is considered as an important key in successful marketing programs. Abdolvand and Reihani (2013) examined the consumption behavior of luxury products among the young people and concentrated on the two fields of brand association and psychological antecedents. They reported that two criteria such as brand association and psychological antecedents significantly influenced the consumption behavior of luxury products among the youth. In addition, the intensity of influence of each of the studied variables was different because of revenue level, education and sexuality.

According to Stokburger-Sauer and Teichmann (2013), despite the fact that the functional value of luxury brands is usually not substantially higher other non-luxury brands, luxury brands can reach substantial price premiums in the market over non-luxury ones. Additionally, in most markets and product categories, the price for female luxury brands is relatively higher. These differences could result from a higher perceived symbolic and social value of such luxury brands that have conventionally been more essential for women than for men.

\section{The proposed study}

This paper investigates the effects of three factors including consumer perceived value, sensitivity to social norms and need for uniqueness on consumer's intention to purchase luxury products based on the theory of planned behavior. The proposed study considers the following five hypotheses,

1. There is a positive relationship between perceived value and consumer's intention to purchase luxury products.

2. There is a positive relationship between sensitivity to social norms and consumer's intention to purchase luxury products.

3. There is a positive relationship between need for uniqueness and consumer's intention to purchase luxury products. 
4. Consumer knowledge is a mediator on relationship between need for uniqueness and consumer's intention to purchase luxury products.

5. Consumer behavior towards famous luxury brands influences on consumer's intention to purchase luxury products.

Fig. 1 demonstrates the structure of the proposed model,

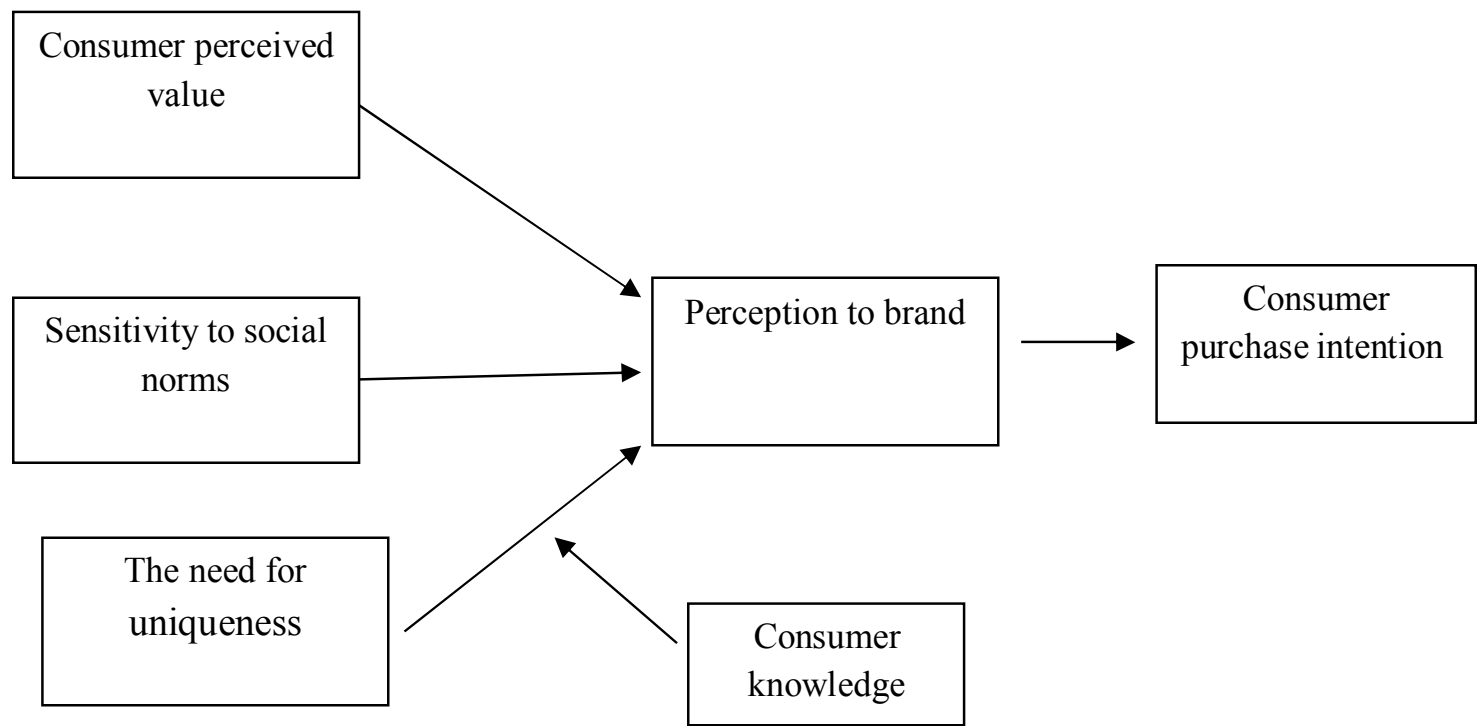

Fig. 1. The proposed model

The proposed study of this paper selects its sample from rich people who live in city of Tehran, Iran. The sample size is calculated as follows,

$n=\frac{N \times z_{\alpha / 2}^{2} \times p \times q}{\varepsilon^{2} \times(N-1)+z_{\alpha / 2}^{2} \times p \times q}$,

where $N$ is the population size, $p=1-q$ represents the yes/no categories, $z_{\alpha / 2}$ is CDF of normal distribution and finally $\varepsilon$ is the error term. Since we have $p=0.5, z_{\alpha / 2}=1.96$ and $N=1,100,000$, the number of sample size is calculated as $n=267$. In our study, we have managed to collect 250 questionniers from our sample size. All questions were desinged in Likert scale from one to five and there were three groups of luxury goods including watch, clothes and eyeglasses. The participants were first asked which type of product they are interested and depending their responses, a customized questionnaire was delivered to them. Fig. 2 demonstrates personal characteristics of the participants.

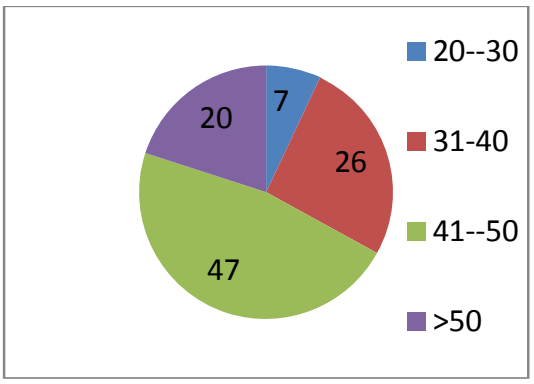

Age

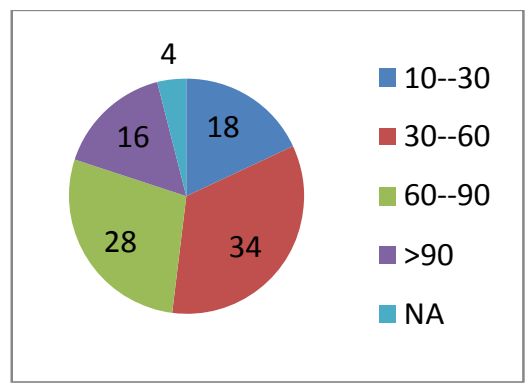

Average income (Million Rials)

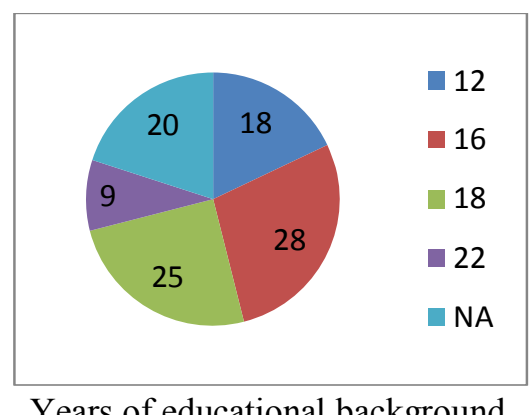

Years of educational background

Fig. 2. Personal characteristics of the participants 
As we can observe from the results of the Fig. 2, most participants are middle age, earn an average income of 60 million Rials and they have, at least, a bachelor degree of science. In our survey, $65.9 \%$ of the participants were single and $53 \%$ of them were female. Before we start the survey, we need to make sure whether the data are normally distributed or not. The implementation of KolmogorovSmirnov test yields a value of 0.412 , which means the data are normally distributed. In addition, Table 1 summarizes Cronbach alpha for different components of the survey.

\section{Table 1}

The summary of Cronbach alpha

\begin{tabular}{|c|c|c|c|}
\hline Properties of latent & Average variance extracted (AVE) & Composite reliability (CR) & Cronbach alpha \\
\hline Need for uniqueness & 0.84 & 0.89 & 0.84 \\
\hline Perceived value & 0.82 & 0.86 & 0.78 \\
\hline Sensitivity to social norms & 0.87 & 0.74 & 0.75 \\
\hline Perception to brand & 0.91 & 0.82 & 0.79 \\
\hline Purchase intention & 0.83 & 0.79 & 0.81 \\
\hline Consumer knowledge & 0.86 & 0.88 & 0.78 \\
\hline
\end{tabular}

As we can observe from the results of Table 1, all components are within acceptable limits and we can complete the survey.

\section{The results}

In this section, we present details of our findings on testing different components of the hypotheses.

Fig. 3 demonstrates the results of path analysis.

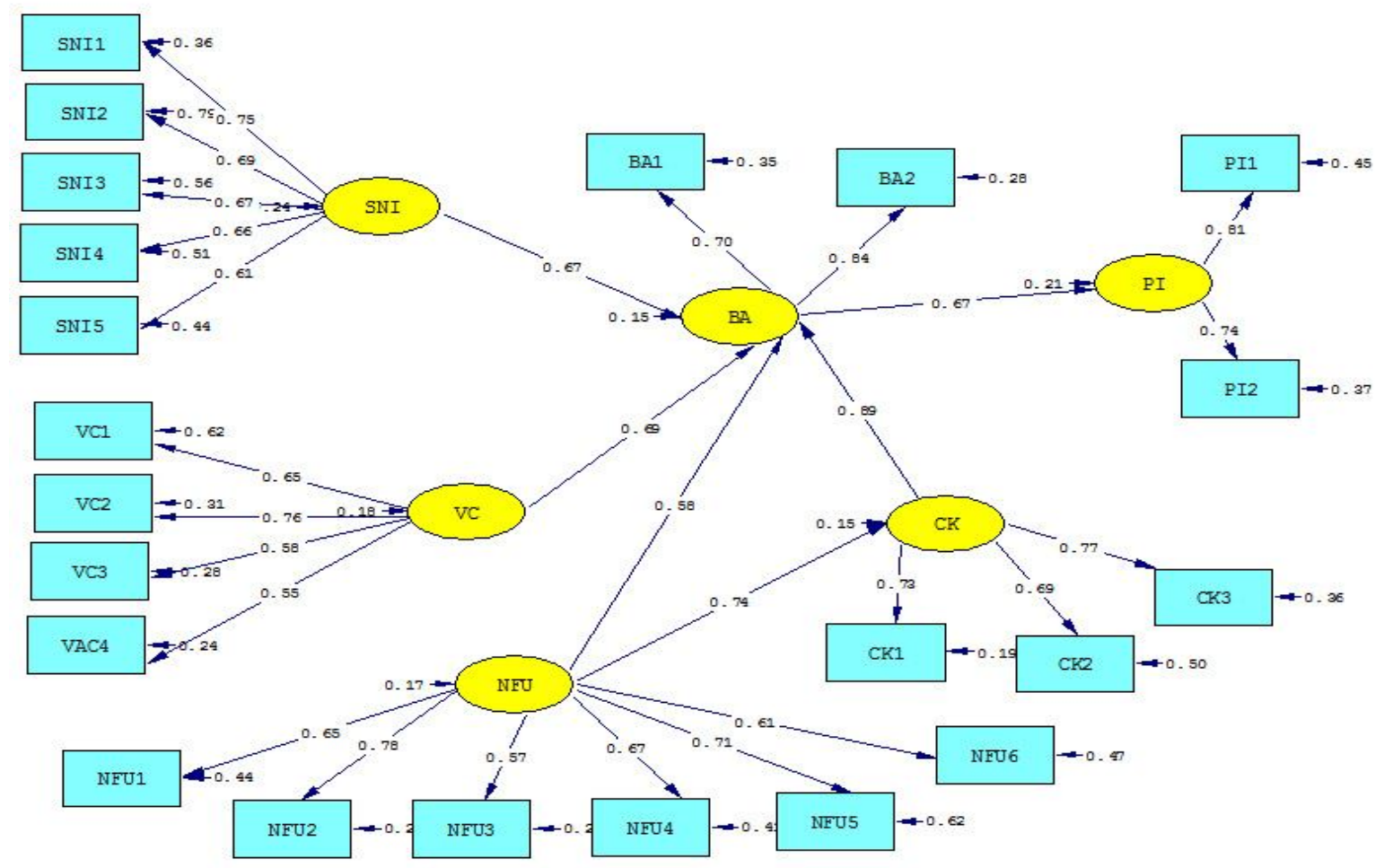

Fig. 3. The summary of the results of path analysis in standard form 
Table 2

The summary of statistical observation

\begin{tabular}{lccc}
\hline Attribute & Limit & Value & Result \\
\hline Chi-square / df & 3 & 2.14 & Suitable \\
RMSEA & $0.05<<0.08$ & 0.074 & Suitable \\
GFI & $>0.9$ & 0.93 & Suitable \\
AGFI & $>0.9$ & 0.9 & Suitable \\
CFI & $>0.9$ & 0.91 & Suitable \\
NFI & $>0.9$ & 0.96 & Suitable \\
NNFI & $>0.9$ & 0.96 & Suitable \\
\hline
\end{tabular}

As we can observe from the results of Table 2, all statistical observations are within acceptable limits and we can analyze the results of paths, which are summarized in Table 3 as follows,

Table 3

The summary of path analysis for hypotheses $1,2,3$ and 5

\begin{tabular}{lcccc}
\hline Hypothesis & Path & Coefficient & t-value & Result \\
\hline 1 & VC-BA & 0.69 & 10.23 & Confirmed \\
2 & SNI-BA & 0.67 & 15.11 & Confirmed \\
3 & NFU-BA & 0.58 & 9.84 & Confirmed \\
5 & BA-PI & 0.67 & 8.38 & Confirmed \\
\hline
\end{tabular}

In order to test the fourth hypothesis, which specifies that consumer knowledge is a mediator on relationship between need for uniqueness and consumer's intention to purchase luxury products, we have to take into account the effects of direct and indirect factor of need for uniqueness on perception to luxury brand. According to Fig. 2, the direct impact is 0.58 and the indirect impact is $(0.74 \times 0.89)=0.65$ and total effect is 0.119 . Therefore, we can confirm the fourth hypothesis and conclude that consumer knowledge plays a mediator between consumer uniqueness and perception to luxury brand.

\section{Conclusion}

In this paper, we have investigated Iranian consumer behavior towards famous luxury brands. The proposed study of this paper considered five hypotheses and using path analysis examined the effects of three factors including consumer perceived value, sensitivity to social norms and need for uniqueness on consumer's intention to purchase luxury products based on the theory of planned behavior. The results of our study have confirmed that all three mentioned components have positive impact on consumer intention on purchasing luxury products. In our survey, being exclusive maintained a factor loading of 0.58 and it maintained lower level of importance compared with other two factors. Having a monopoly product with relative weight of 0.78 is the most important factor. The surveyed people believed that a luxury product such as Rolex watch must be sold only in limited numbers of stores and if it is sold among regular products, people prefer not to purchase such product. Perception value with factor loading of 0.69 plays an essential role on perception value. Our surveyed people believed pricing luxury products must be done very carefully since an unrealistic price could give signal to consumer to switch from one product to another one.

\section{Acknowledgment}

The authors would like to thank the anonymous referees for constructive comments on this paper, which has made it easier to read. 


\section{References}

Abdolvand, M.A., Reihani, N. (2013). The effect of brand association in psycho-social and psychopersonality antecedents a conceptual model of conspicuous consumption among youth adult. Research Journal of Applied Sciences, Engineering and Technology, 6(6), 1012-1022.

Achabou, M.A., \& Dekhili, S. (2013). Luxury and sustainable development: Is there a match? Journal of Business Research, 66 (10), 1896-1903.

Albrecht, C.-M., Backhaus, C., Gurzki, H., \& Woisetschläger, D.M. (2013). Drivers of brand extension success: What really matters for luxury brands. Psychology and Marketing, 30(8), 647659.

Hwang, J., \& Han, H. (2014). Examining strategies for maximizing and utilizing brand prestige in the luxury cruise industry. Tourism Management, 40, 244-259.

Pina, J.M., Dall'Olmo Riley, F., \& Lomax, W. (2013). Generalizing spillover effects of goods and service brand extensions: A meta-analysis approach. Journal of Business Research, 66(9), 14111419.

Stokburger-Sauer, N.E., \& Teichmann, K. (2013). Is luxury just a female thing? The role of gender in luxury brand consumption. Journal of Business Research, 66 (7), 889-896.

Yu, C.-C., Lin, P.-J., Chen, C.-S. (2013). How brand image, country of origin, and self-congruity influence internet users' purchase intention. Social Behavior and Personality, 41(4), 599-611. 